\title{
Akıllı Telefon Bağımlılığı ile Sürücü Davranışları Arasındaki İlişki
}

\author{
Serpil Büyükbaş ${ }^{1}$ (D), M. Ehil Tekin ${ }^{1}$ (D), Burcu Tekeş $2,3 *$ (iD \\ ${ }^{1}$ Psikoloji Bölümü, FMV Işık Üniversitesi, İstanbul Türkiye. \\ ${ }^{2}$ Psikoloji Bölümü, İstanbul Ayvansaray Üniversitesi, İstanbul Türkiye. \\ ${ }^{3}$ Güvenlik Araştırma Birimi, Psikoloji Bölümü, Orta Doğu Teknik Üniversitesi, Ankara Türkiye.
}

\section{Özet}

Türkiye İstatistik Kurumu 2018 yılı verilerine göre cep telefonu abone sayısı son 10 yılda \%30 oranında artış göstererek 80637671'e ulaşmışıı (Türkiye İstatistik Kurumu [TÜIKK], 2018). Cep telefonu kullanımındaki bu hızlı artışa bağlı olarak telefon kullanım alanları genişlemiş ve trafik ortamına da girmiştir. Bu duruma bağlı olarak trafik ortamında telefon kullanımı sürücülerin dikkatlerinin dağılmasına neden olmaktadır. Dikkati dağınık sürücülük ise, trafik ortamında pek çok soruna yol açmakta ve sürücü davranışlarını etkilemektedir. Bu bilgilerden yola çıkarak, bu çalışmada sürücü davranışları ile sürücülerin akıllı telefon bağımlılıkları arasındaki ilişkinin incelenmesi amaçlanmıştır. Çalışmanın örneklemini 18-42 yaş aralığındaki ehliyeti olan 47'si kadın 87'si erkek olmak üzere toplam 134 katılımcı oluşturmaktadır. Çalışmada Sürücü Davranışları Ölçeği (SDÖ) (Lajunen ve Özkan, 2004) ve Akıllı Telefon Bağımlılığı Ölçeği’nin (SAS) (Noyan, Enez-Darçın, Nurmedov, Yılmaz ve Dilbaz, 2015) kısa formu kullanılmıștır. Yapılan hiyerarșik regresyon analizi sonuçlarına göre, hatalar, sıradan ihlaller, agresif ihlaller ve ihmaller ile akıllı telefon bağımlılı̆̆ arasında pozitif yönde anlamlı ilişkiler bulunmuştur. Ayrıca, sıradan ihlaller ile cinsiyet ve günlük akıllı telefon kullanım sıklığı arasında da pozitif yönde anlamlı bir ilişsi bulunmuştur. Çalışmanın bulguları ilgili literatür kapsamında tartışılmıştır.

Anahtar Kelimeler: sürücü davranışı, akıllı telefon bağımlılığı, dikkati dağınık sürücülük

\section{The Relationship between Smart Phone Addiction and Driver Behaviors}

\begin{abstract}
According to the Turkey Statistical Institute numbers revealed in 2018, the number of mobile phone subscribers increased by $30 \%$ and reached 80637671 in the last 10 years (TurkStat, 2018). Due to this rapid increase in the use of mobile phones, the use of the phone has expanded and entered the traffic environment. In recent years, the use of smart phones in the traffic flow due to increased phone usage causes the distractions of the drivers. Distracted driving leads to many problems in the traffic environment and affects driver behavior. In this study, it is aimed to investigate the relationship between driver behavior and smartphone addiction of drivers. The sample of the study consisted of 47 females and 87 males a total of 134 participants between the ages of 18 to 42 . As measurement, Driver Behavior Questionnaire (DBQ) (Lajunen \& Özkan, 2004) and short-form of the Smart Phone Addiction Scale (SAS) (Noyan et al., 2015) were used. According to the hierarchical regression analysis results, smart phone addiction was found as positively related to errors, lapses, ordinary and aggressive violations. Also, ordinary violations were positively related to both gender and frequency of daily smartphone usage. Results were discussed on the framework of related literature.
\end{abstract}

Keywords: driver behavior, smart phone addiction, distracted driving

\footnotetext{
* Illetişim / Contact: Burcu Tekeş, Psikoloji Bölümü, İstanbul Ayvansaray Üniversitesi, İstanbul Türkiye. E-Posta / Email: burcutekes@gmail.com Gönderildiği tarihi / Date submitted: 20.01.2019, Kabul edildiği tarih / Date accepted: 18.04.2019

Alıntı / Citation: Büyükbaş, S., Tekin, M. E. ve Tekeş, B. (2019). Akıllı telefon bağımlılı̆̆ı ile sürücü davranışları arasındaki ilişki. Trafik ve Ulaşım Araştırmaları Dergisi, 2(1), 16-29.
} 


\section{Akıllı Telefon Bağımlılığı ile Sürüicü Davranışları Arasındaki İlişki}

Dünya Sağlık Örgütü (DSÖ)'nün raporuna göre, dikkati dağınık sürücülük, sürücülerin, sürüş esnasında dikkatlerinin araç hakimiyetinden, diğer yol kullanıcılarından ve yol kurallarından uzak olması olarak tanımlanmaktadır (DSÖ, 2011). Bir diğer tanıma göre, dikkati dağınık sürücülük, dikkatin güvenli sürücülük için kritik olan aktivitelerden uzaklaşarak dikkat dağıtıcı başka bir aktiviteye yönelmesidir (Regan, 2007). Dikkat dağınık şekilde araç kullanmanın önemi, dünya çapında kural koyucular tarafından fark edilmiş olup, bu konuda yapılan çalışmalar ve alınan önlemler gün geçtikçe artmaktadır (DSÖ, 2011). Yol Kullanıcılarının Güvenlik Tutumlarına Yönelik Avrupa Araştırması (ESRA, 2016), dikkati dağınık sürücülüğün son iki yıl içinde arttığı sonucunu ortaya koymuştur. Bu rapora göre, erkekler kadınlara göre, gençler yaşlılara göre sürüş sırasında akıllı telefon kullanımını daha kabul edilebilir ve daha az riskli bulmaktadırlar.

Dikkati dağınık sürücülük görsel, bilişsel, fiziksel ve işitsel olmak üzere dört kategoride değerlendirilmektedir (DSÖ, 2011). Dikkati dağınık sürücülüğe sebep olabilecek faktörler ise çeşitli nesnelerin varlığı (navigasyon sistemleri, reklam panoları, yiyecekler, içecekler), olaylar (kazaya şahit olmak, şimşek çakması), yolcular (sohbet etmek), diğer yol kullanıcıları (bisikletliler, yayalar ya da diğer taşıtlar), hayvanlar ya da içsel uyaranlar (ağrı, öksürme ya da hapşırma refleksi ya da düşünceler) olarak özetlenebilir (Regan, Hallet ve Gordon, 2011; Regan, Lee ve Young, 2008). Dikkati dağınık sürücülüğe neden olan bu faktörlere ek olarak sürücülerin akan trafik ortamında cep telefonunu kullanması da gittikçe artan bir görülme sıklığına sahiptir.

Yaygınlaşan akıllı telefon kullanımı, tüm dünyada trafikte bir risk faktörü oluşturmaktadır. Dünya Sağlık Örgütü (DSÖ) 2011 yılı raporuna göre, dikkati dağınık sürücülüğün en güçlü yordayıcısı, trafik ortamında sürücülerin cep telefonu kullanmasıdır. Yapılan araştırmalara göre, sürüş esnasında cep telefonu ile konuşan sürücülerin kaza yapma olasılıkları diğer sürücülere göre dört kat daha fazladır (DSÖ, 2011). Sürüş sırasında telefonla konuşmak, mesaj okumak ya da mesaj yazmak gibi aktivitelerin telefon kullanımına bağlı olarak yaygınlaşması ise tüm yol kullanıcılarını tehdit altına sokmaktadır. Bu sebeple sürüş esnasında cep telefonu kullanımı, sürücülerin tepki hızında, akan trafiğgi uygun şekilde takip etmelerinde ve trafikteki anlık değişikliklere ayak uydurmalarında önemli eksiklikler oluşturmaktadır (Asbridge, Brubacher ve Chan, 2012). Bu bilgiler dahilinde, yapılan çalışmalar, sürücülerin cep telefonu kullanmak gibi dikkat dağıtıcı etkenlerle meşgul olmasının sürüş hatası yapmalarındaki önemli sebeplerinden birisi olduğunu göstermektedir (Saiprasert, Supakwong, Sangjun ve Thajchayapong, 2014). Sonuç olarak, sürücülerin sürüş esnasında akıllı telefon kullanmak gibi dikkat dağıtıcı davranışlarının sürücü davranışlarını da etkileyeceği düşünülmektedir.

\subsection{Sürücü Davranışları}

Sürücü davranışları, sürücülerin araç kullanırken ne yapmayı tercih ettikleri olarak özetlenebilmektedir (Elander, West ve French, 1993). Sürücü davranışları üzerinde, sürücülerin yaşları, cinsiyetleri, aile geçmişleri, kişilik özellikleri, risk algıları gibi pek çok sosyal, demografik, psikolojik ve yasal (trafik yasa ve yönetmeliklerince uygulanan) değişkenin etkili olduğu görülmektedir (Boyce ve Geller, 2002; Dahlen ve White, 2006; Zhang, Xing, Qian, Jia ve Liu, 2018; Wang, Zheng ve Fleiter, 2016, Li, Yan ve Wong, 2015; Xu, Liu, Sun, Zhang, Qu ve Ge, 2018). İlgili literatür incelendiğinde, sürücü davranışlarının hatalar, ihlaller ve ihmaller olmak üzere üç boyutta ele alınabildiği görülmektedir. Hatalar "planlanan davranışların niyet edilen sonuca ulaşmadaki başarısızlığı" olarak tanımlanmaktadır. Sürücülerin akan trafik ortamında trafik işaretlerini yanlış anlaması, diğer araçların sinyallerini fark etmeyip araçları sollamaya çalışması hatalara örnek gösterilebilecek sürücü davranışlarındandır. Bir diğer boyut

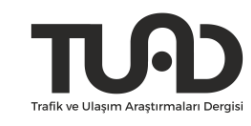


olan 'ihlaller', "potansiyel tehlikeli bir sistem içerisinde güvenli bir akışı sağlamak için gerekli olan davranışları kasıtlı olarak gerçekleştirmemek" olarak tanımlanabilmektedir (Öztürk, 2017; Reason, Manstead, Stradling, Baxter ve Campbell, 1990). İhlaller kendi içerisinde siradan ihlaller ve agresif ihlaller olarak iki farklı boyutta incelenmektedir. Sıradan ihlaller, sürücülerin diğer yol kullanıcılarını incitme niyeti olmadan sergiledikleri ihlalledir. Sürücülerin istikametine uygun olmayan şeridi kullanması, şehir içi yollarda ya da otobanda hız sınırını aşması sıradan ihlal davranışlarına örnektir. Agresif ihlaller ise sürücülerin, diğer yol kullanıcılarını bilinçli olarak incitmeye yönelik davranışlar sergilemesidir (Özer ve Öz, 2018). Sürücülerin diğer araçlara olan takip mesafesini çok kısa tutması ve diğer araçları sıkıştırması agresif ihlallere örnek gösterilebilir. İhmaller ise trafik ortamında sürücülerin yaptıkları, kötü konsantrasyondan kaynaklanan unutkan davranışlardır. Örneğin sürücülerin araçlarını çok katlı park alanında nereye bıraktıklarını unutması, ihmallere örnek gösterilebilecek davranışlardandır (Reason ve ark., 1990).

Sürücü davranışları üzerinde yapılan çalışmalar, dikkati dağınık şekilde araç kullanmanın önemli bir risk faktörü olduğunu ortaya koymaktadır (Young, Salmon ve Cornelissen, 2013). Trafik ortamındaki dikkat dağınıklığı, sürücülerin sürüş esnasında dikkatlerini yol ve araçtan farklı bir yere yönlendirmesi olarak tanımlanmakta (Gershon, Zhu, Klauer, Dingus ve SimonsMorton, 2017) ve sürücü davranışlarının özellikle hatalar boyutu ile güçlü ilişki içerisinde bulunduğunu ortaya koymaktadır (Young ve ark., 2013). Dikkati dağınık sürücülük ile ilişkili olabilecek birçok etmen olmakla beraber, sürüş esnasında telefon kullanımının özellikle üzerinde durulan bir konu olduğu görülmektedir (Regan ve ark., 2008). Bu sebeple, bu çalışmada sürücülerin akıllı telefon bağımlılıklarının sürücü davranışları ile ilişkisinin incelenmesi amaçlanmıştır.

\subsection{Akıllı Telefon Bağımlıığı}

Teknolojideki ilerlemeler sayesinde kişiler akıllı telefonlar aracılığıyla istenilen bilgilere yer ve zaman fark etmeksizin kolayca ulaşabilmektedirler. Akıllı telefonlar, iletişim kurma ve bilgi ulaşımı kolaylığının yanı sıra fotoğraf ve video çekme, görüntülü konuşma, navigasyon ve sosyal medya erişimi gibi çeşitli ihtiyaçları da gidermektedir (Aktaş ve Yılmaz, 2017). Öte yandan, akıllı telefon kullanımının özellikleri gençler arasındaki gittikçe artan aşırı kullanımı (Dragutinovic ve Twisk, 2005; Lepp, Li, Barkley ve Salehi-Esfahani, 2015) bunun bir bağımlılık olduğu yönünde tartışmaları doğurmaktadır (Lepp ve ark., 2015). Araştırmalar, akıllı telefon aşırı kullanımının, internet bağımlılığı ile oldukça benzer şekilde zorlayıcı-dürtüsel bozukluklarla benzer bir yapıda olduğunu ortaya koymaktadır (DSM V, 2008). Yapılan çalışmalarda akıllı telefonlarda bulunan uygulamaların çok sık kontrol edilmesinin, stres, uyku sorunları, düşük akademik ve fiziksel performans ile bağlantılı olduğu bulunmuştur (Thomée, Härenstam ve Hagberg, 2011).

Akıllı telefon kullanımının özellikle gençler arasında çok yaygın olduğu görülmektedir (Dragutinovic ve Twisk, 2005; Lepp ve ark., 2015; Uzgören, Şengür ve Yiğit, 2013). Yapılan bir çalışmaya göre, 15-24 yaş arasındaki gençler özellikle mesajlaşma ile ilgili servisleri daha fazla kullanmakta ve günde en az bir saatlerini telefon ile konuşarak geçirmektedir (Dragutinovic ve Twisk, 2005). Benzer şekilde 16-24 yaş arası gençlerin \%90'ının akıllı telefonları bulunduğu bilinmektedir (Fowler ve Noyes, 2017). Amerika'da yapılan bir çalışmanın verilerine göre ise 18 yaş üzeri akıllı telefon kullanıcılarının \%52'si cep telefonlarını her 5 ile 10 dakikada bir kontrol etmektedir (Bank of America, 2015). Yapılan çalışmalar genç sürücülerin trafik kazasına karışma oranları ve ihlal yapmak gibi riskli sürücü davranışlarını daha fazla sergilediklerini göstermektedir (Hassan ve Abdel-Aty, 2013; Lam, 2003; Sümer, Lajunen ve Özkan, 2002). Sürüş esnasında akıllı telefon kullanımının sürücülerin ihlal yapma olasılıklarını arttırdığı söylenmektedir (Drews ve Strayer, 2008). Genç sürücülerin hali hazırda

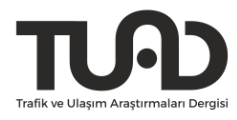


trafikteki en önemli risk gruplarından oldukları bilgisinden hareket edilirse, akıllı telefon bağımlılığının tüm yol kullanıcıları için bu riski arttırdığı düşünülmektedir.

\subsection{Amaç}

Yapılan çalışmalarda sürüş esnasında akıllı telefon kullanan sürücülerin, riskli sürücü grubuna dahil oldukları ve trafikte daha fazla riskli davranışlar gösterdikleri yönünde bulgular mevcuttur (Eby ve Vivoda, 2003; Yıldız ve Selek, 2018). Bu sebeple, bu çalışmada akıllı telefon bağımlılığı ile sürücü davranışları arasındaki ilişkinin incelenmesi amaçlanmaktadır.

\section{Yöntem}

\section{1. Örneklem}

Bu çalışmanın örneklemini 47'si kadın (\% 35.1) ve 87'si erkek (\% 64.9) olmak üzere, ehliyet sahibi olan toplam 134 kişi oluşturmaktadır. Katılımcıların yaş aralığı 18-42 arasında değişmekte olup, yaş ortalaması 22.74'tür $(S S=5.38)$. Eğitim durumlarının betimsel analizine göre; katılımcıların \% 7'si $(N=1)$ ilkokul mezunu iken, \% 2.2'si $(N=3)$ ortaokul mezunu, \% 11.9'u ( $N=16)$ lise mezunu, \% 78.4'ü $(N=105)$ lisans mezunu, \% 5.2'si $(N=7)$ yüksek lisans mezunu ve son olarak \% 1.5'i $(N=2)$ doktora mezunudur. Günlük ortalama telefon kullanım süresi incelendiğinde, katılımcıların \% 10.4'ü $(N=14) 0$-2 saat, \% 32.8'i $(N=44) 2$-4 saat, \% 29.1'i $(N=39) 4-6$ saat, \% 27.6'sı $(N=37) 6$ saatten fazla telefon kullandıklarını belirtmişlerdir.

\subsection{Veri Toplama Araçları}

Veriler sürücülere demografik bilgi formu, Sürücü Davranışları Ölçeği (SDÖ) ve Akıllı Telefon Bağımlılığı Ölçeği (ATBÖ) uygulanarak elde edilmiştir.

\subsubsection{Sürü̈cü davranışları ölçeği (SDÖ).}

Reason ve ark. (1990) tarafından geliştirilen SDÖ, sürücü davranışlarını ölçmeyi amaçlayan, kendini değerlendirme türü bir ölçek olup 28 maddeden oluşmaktadır. Ölçek, Cronbach Alfa iç tutarlılık katsayıları .56 ile .86 arasında değişen 4 boyuttan oluşmaktadır (Lajunen ve Özkan, 2004). Ayrıca bu çalışmada Cronbach's Alfa iç tutarlılık katsayıları; 'hatalar' için .88, 'sıradan ihlaller' için .84, 'agresif ihlaller' için .71, 'ihmaller' için .85 olarak bulunmuştur. 'Hatalar' adı verilen birinci boyut 8 maddeden oluşmakta ve 'Trafik ışılklarında üçüncü vitesle kalkış yapmaya çalışmak' gibi maddeleri içermektedir. 'sıradan ihlaller' adı verilen ikinci boyut 9 maddeden oluşmakta ve 'Solda yavaş giden bir aracın sağından geçmek' gibi maddeleri içermektedir. 'Agresif ihlaller' adı verilen üçüncü boyut 3 maddeden oluşmakta ve 'Trafikte sinirlendiğiniz bir sürücüyü takip edip ona haddini bildirmeye çalışmak' gibi maddeleri içermektedir. Son olarak 'ihmaller' adı verilen dördüncü boyut ise 8 maddeden oluşmakta ve 'Bir aract sollarken ya da şerit değiştirirken dikiz aynasından yolu kontrol etmemek' gibi maddeleri içermektedir. Maddeler 1 (Hiçbir zaman) ve 6 (Her zaman) arasında değişen 6 puanlı likert tipi ölçek aracılığıyla değerlendirilmektedir.

\subsubsection{Akıllı telefon bağımlılığı ölçeği (ATBÖ).}

Bu çalışmada Kwon ve ark. (2013) tarafından geliştirilen 33 maddelik ölçeğin, Noyan ve ark. (2015) tarafından geçerlik ve güvenirlik çalışması yapılmış olan kısa formu kullanılmıştır. ATBÖ kısa formu, bireylerin akıllı telefon kullanımına yönelik tutumlarını ve davranışlarını belirlemeyi amaçlayan, kendini değerlendirme türü bir ölçek olup 10 maddelik tek faktörlü bir yapıdan oluşmaktadır. Ölçek, öz-bildirime dayalı "Çevremdeki insanlar akıllı telefonumu çok fazla kullandığımı söylerler." şeklinde maddelerden oluşmakta olup, 1 (Kesinlikle hayır) ile 6 (Kesinlikle evet) arasında değişen 6 puanlı likert tipi ölçek aracılığıyla değerlendirilmektedir. Ölçekten alınan yüksek puan, yüksek bağımlılık riskine işaret etmektedir. Bu çalışmada

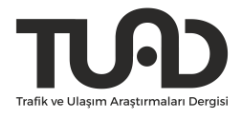


hesaplanan Cronbach's Alfa iç tutarlılık katsayısı, ölçeğin Noyan ve ark. (2015) tarafından yapılan orijinal uyarlaması ile tutarlı olarak .87 olarak bulunmuştur.

\subsection{Kişisel Bilgi Formu}

Kişisel bilgi formunda; cinsiyet, yaş, kilometre yaşı gibi değişkenlerin yanı sıra, günlük ortalama akıllı telefon kullanımı süresi ve kişinin trafikte akıllı telefonunu kullanım sıklığı gibi çeşitli demografik sorulara da yer verilmiştir.

\section{4. İşlem}

Çalışmanın başında öncelikle Işı Üniversitesi Psikoloji Bölümünden ilgili etik izinler alınmıştır. Daha sonra katılımcılara çalışmaya başlamadan önce bilgilendirilmiş onam formu sunulup, araştırmaya katılımlarının gönüllülük esasına dayandığı belirtilmiş ve ardından çalışmaya dahil edilmişlerdir. Çalışmaya yalnızca ehliyet sahibi ve aktif olarak araç kullanan katılımcılar dahil edilmiştir. Uygulama ortalama 15 dakika sürmüştür ve veriler yaklaşık olarak on günde toplanmıştır. Ölçekler katılımcılara çevrimiçi bir internet sayfası olan www.surveey.com aracılığıyla ulaştırılmıştır. Bulgular, IBM SPSS Statistics 21 programı aracılığ

\section{Bulgular}

\subsection{Değişkenler Arasındaki İlişkiler}

Değişkenler arasındaki ilişkiler öncelikle korelasyon analizi ile incelenmiştir (bkz. Tablo 1). Demografik değişkenlere bakıldığında yaşın sadece kilometre yaşı ile pozitif yönde ilişkili olduğu görülmektedir $(r=.50, p=.000)$. Cinsiyet, kilometre yaşı $(r=.43, p=.000)$, siradan ihlaller $(r=.23, p=.000)$ ve agresif ihlaller $(r=.17, p=.045)$ ile pozitif yönde ilişkili iken, günlük ortalama akıllı telefon kullanımı $(r=-.23, p=.000)$ ve akıllı telefon bağımlılığı $(r=-$ $.20, p=.018)$ ile negatif yönde ilişkili bulunmuştur. Kilometre yaşı akıllı telefon bağımlılığı ( $r$ $=-.17, p=.018$ ) ile negatif yönde ilişkili bulunmuştur. Trafikte akıllı telefon kullanım süresinin, günlük ortalama akıllı telefon kullanımı $(r=.30, p=.000)$ ve siradan ihlallerle pozitif yönde ilişkili olduğu görülmüştür $(r=.18, p=.041)$. Son olarak günlük ortalama akıllı telefon kullanımının ise akıllı telefon bağımlılığı $(r=.41, p=.018)$ ile pozitif yönde ilişkili olduğu bulunmuştur.

Tablo 1. Değişkenler Arasındaki İlişkiler

\begin{tabular}{|c|c|c|c|c|c|c|c|c|c|c|}
\hline Değişken & 1 & 2 & 3 & 4 & 5 & 6 & 7 & 8 & 9 & 10 \\
\hline Yaşınız (1) & 1 & & & & & & & & & \\
\hline Cinsiyetiniz (2) & .084 & 1 & & & & & & & & \\
\hline Kilometre yaşı (3) & $.496^{* *}$ & $.425^{* *}$ & 1 & & & & & & & \\
\hline $\begin{array}{l}\text { Trafikte akıllı telefon } \\
\text { kullanımı (4) }\end{array}$ & -.080 & .104 & .053 & 1 & & & & & & \\
\hline $\begin{array}{l}\text { Günlük ortalama akı1lı } \\
\text { telefon kullanımı (5) }\end{array}$ & -.101 & $-.229^{* *}$ & -.150 & $.300^{* *}$ & 1 & & & & & \\
\hline Hatalar (6) & -.110 & 145 & .007 & .110 & .087 & 1 & & & & \\
\hline Siradan ihlaller (7) & -.080 & $.234^{* *}$ & .152 & $.177^{*}$ & .125 & $.743^{* *}$ & 1 & & & \\
\hline Agresif ihlaller (8) & -.026 & $.173^{*}$ & .125 & .162 & .049 & $.437^{* *}$ & $.566^{* *}$ & 1 & & \\
\hline İhmaller (9) & -.160 & .038 & -.062 & .099 & .102 & $.840^{* *}$ & $.680^{* *}$ & $.351^{* *}$ & 1 & \\
\hline $\begin{array}{l}\text { Akıllı telefon bağımlılı̆̆ } 1 \\
\text { (10) }\end{array}$ & -.132 & $-.204^{*}$ & $-.172^{*}$ & .136 & $.413^{* *}$ & $.472^{* *}$ & $.414^{* *}$ & $.237^{* *}$ & $.481^{* *}$ & 1 \\
\hline
\end{tabular}


Akıllı telefon bağımlılı̆̆ı ile sürücü davranışları arasındaki ilişkiler incelendiğinde, akıllı telefon bağımlılığının hatalar $(r=.47, p=.000)$, sıradan ihlaller $(r=.41, p=.000)$, agresif ihlaller $(r=.24, p=.000)$, ve ihmaller $(r=.48, p=.000)$ ile pozitif yönde ilişkiler içinde olduğu görülmüştür.

\subsection{Demografik Değişkenler ve Akıllı Telefon Bağımlıı̆ğının Sürücü Davranışları ile İlişkisi}

Akıllı telefon bağımlılığının sürücü davranışları ile ilişkisinin incelenmesi için hiyerarşik regresyon analizi kullanılmıştır (bkz. Tablo 2). Sürücü davranışları ölçeğinin dört alt boyutu için analizler ayrı ayrı yapılmıştır. Tüm analizlerde yaş, cinsiyet, kilometre yaşı, günlük akıllı telefon kullanım süresi kontrol değişkeni olarak birinci adımda analize dahil edilmiştir.

Sürücü davranışları ölçeğinin hatalar alt boyutunun ele alındığı ilk analizde ilk adımda yaş, cinsiyet, kilometre yaşı ve günlük akıllı telefon kullanım süresi ile hatalar arasındaki ilişki incelenmiş ancak anlamlı bir sonuç bulunamamıştır. İkinci adımda akıllı telefon bağımlılığı ile hatalar arasındaki model anlamlıdır, $\left(\Delta R^{2}=.24, F(5,132)=43.52, p=.000\right)$. Buna göre akıllı telefon bağımlılığ , hatalar ile pozitif yönde anlamlı olarak ilişkilidir $(\beta=.55, p=.000)$.

Sıradan ihlaller ve akıllı telefon bağımlılığı ilişkisini inceleyen ikinci analizde, ilk adımda kontrol değişkeni olarak yaş, cinsiyet, kilometre yaşı ve günlük akıllı telefon kullanım süresi ile sıradan ihlaller arasındaki ilişkiyi açıklayan modelin anlamlı olduğu görülmektedir $\left(\Delta R^{2}=\right.$ $.12, F(4,132)=4.48, p=.002)$. İlk adımda cinsiyet değişkeni (erkek olmak) ile sıradan ihlaller pozitif yönde anlamlı olarak ilişkilidir $(\beta=.45, p=.019)$. Akıllı telefon bağımlılığı ile sıradan ihlaller arasındaki ilişkiyi inceleyen ikinci model yine anlamlı bulunmuştur $\left(\Delta R^{2}=.18, F(5\right.$, $132)=33.36, p=.000)$. Buna göre akıllı telefon bağımlılı̆̆ ile sıradan ihlaller $(\beta=.47, p=$ .000) pozitif yönde anlamlı olarak ilişkilidir.

Agresif ihlaller ve akıllı telefon bağımlılığının incelendiği bir sonraki regresyon analizinin birinci adımında yine demografik değişkenler analize dahil edilmiş, ancak anlamlı bir sonuç bulunamamıştır. İkinci adımda akıllı telefon bağımlılığı ile agresif ihlaller arasındaki ilişkiye bakıldığında model anlamlı bulunmuştur $\left(\Delta R^{2}=.07, F(5,132)=3.49, p=.006\right)$. Buna göre akıllı telefon bağımlılığı ile agresif ihlaller $(\beta=.37, p=.002)$ pozitif yönde anlamlı olarak ilişkilidir.

Son olarak, ihmaller üzerinde akıllı telefon bağımlılığının incelendiği bir sonraki regresyon analizinin birinci adımında kontrol değişkeni olarak yine yaş, cinsiyet, kilometre yaşı ve trafik ortamında akıllı telefon kullanım sıklığı ele alınmış ancak modelde anlamlı bir sonuç bulunamamıştır. İkinci adımda akıllı telefon bağımlılığı ile ihmaller arasındaki ilişki incelendiğinde model anlamlı bulunmuştur $\left(\Delta R^{2}=.23, F(5,132)=9.33, p=.000\right)$. Buna göre sanal yönelimli ilişki ile ihmaller arasında pozitif yönde anlamlı bir ilişki bulunmaktadır $(\beta=$ $.49, p=.000)$. 
Tablo 2. Demografik değişkenler ve akıllı telefon bağımlılığının sürücü̈ davranışları ile ilişkisine yönelik hiyerarşik regresyon analizi

\begin{tabular}{|c|c|c|c|c|c|c|c|c|c|c|c|c|c|c|c|c|c|c|c|c|}
\hline & \multicolumn{4}{|c|}{ 1.Hatalar } & \multicolumn{6}{|c|}{ 2.Sıradan İhlaller } & \multicolumn{4}{|c|}{ 3.Agresif İhlaller } & \multicolumn{6}{|c|}{ 4.İhmaller } \\
\hline & $R^{2}$ & $\Delta R^{2}$ & $F$ & $\beta$ & $p$ & $R^{2}$ & $\Delta R^{2}$ & $F$ & $\beta$ & $p$ & $R^{2}$ & $\Delta R^{2}$ & $F$ & $\beta$ & $p$ & $R^{2}$ & $\Delta R^{2}$ & $F$ & $\beta$ & $p$ \\
\hline 1. & .05 & .05 & 1.77 & & .140 & .12 & .12 & 4.48 & & .002 & .05 & .05 & 1.84 & & .125 & .04 & .04 & 1.33 & & .263 \\
\hline Yaş & & & & -.03 & .228 & & & & -.05 & .081 & & & & -.03 & .347 & & & & -.04 & .117 \\
\hline Cinsiyet & & & & .37 & .064 & & & & .45 & .019 & & & & .41 & .111 & & & & .15 & .423 \\
\hline Kilometre yaşı & & & & .00 & .878 & & & & .05 & .088 & & & & .04 & .232 & & & & .00 & .939 \\
\hline Günlük akıllı telefon kullanma sıklığı & & & & .12 & .172 & & & & .19 & .027 & & & & .13 & .265 & & & & .09 & .230 \\
\hline Akıllı Telefon Bağımlılı̆ğ & & & & .55 & .000 & & & & .47 & .000 & & & & .37 & .002 & & & & .49 & .000 \\
\hline
\end{tabular}




\section{Tartışma}

Bu çalışmada, sürücülerin akıllı telefon bağımlılığı ile sürücü davranışları arasındaki ilişkinin incelenmesi amaçlanmıştır. Daha önce yapılan çalışmalar incelendiğinde her iki değişkenin de dikkati dağınık sürücülük çerçevesinde birleştiği görülmektedir. İlgili literatür tarandığında, dikkati dağınık sürücülüğün sürüş performansı, risk algısı ve kişilik özellikleri gibi konular ile birlikte çalışıldığı görülürken, dikkati dağınık sürücülüğün akıllı telefon bağımlılı̆̆ın özelinde ele alınarak, sürücü davranışları ile ilişkisinin incelendiği bir çalışmaya rastlanmamıştır (Parr ve ark., 2016; Engelberg, Hill, Rybar ve Styer, 2015; Weller, Shackleford, Dieckmann ve Slovic, 2013).

Çalışmada sürücü davranışı alt boyutu olan hatalar ile akıllı telefon bağımlılığı arasında pozitif yönde anlamlı bir ilişki olduğu bulunmuştur. $\mathrm{Bu}$ bulgular doğrultusunda araç kullanımı esnasında sürücülerin telefon ile konuşması, mesaj yazması ve mesaj okuması gibi dikkat dağıtıcı davranışların, akan trafik ortamında hatalı davranışlara sebebiyet verebileceği düşünülmektedir (Regan ve ark., 2008). Bir diğer yaklaşım olarak, akıllı telefon bağımlılığı ölçeğinin uzun formunun kullanıldığı bir çalışmada ele alınan sanal yönelim alt boyutu, bireylerin kişilerarası ilişkilerini çoğunlukla sosyal medya üzerinden oluşturduğu ve sanal ortamda kurdukları ilişkilere gerçek hayattaki ilişkilerinden daha çok güvenmeleri olarak tanımlanmıştır (Şata, Çelik, Ertürk ve Taş, 2016). Bu durum bireylerin akıllı telefonundaki değişiklikleri sık sık takip etmelerine neden olmaktadır. Her ne kadar bu çalışmada akı1lı telefon bağımlılığı ölçeğinin kısa formu kullanılmış olsa da kavram olarak ele alındığında kişilerin sosyal medyayı sık kullanmalarının sürücü hataları ile ilişkili olması şaşırtıcı değildir.

İlgili literatür incelendiğinde genç sürücülerin daha fazla hata yaptıkları bulunmuştur (Fındık, Lajunen ve Özkan, 2018). Bu bilgiden yola çıkarak hatalı davranışlar ile yaş arasında negatif yönde anlamlı bir ilişki beklenmiştir fakat iki değişken arasında anlamlı bir ilişki bulunamamıştır. Çalışmanın örnekleminin genellikle genç sürücülerden oluşmasının bu durum üzerinde etkili olduğu düşünülmektedir. Bu bulgu araştırmada incelenen diğer değişkenler ile yaş arasında da anlamlı ilişkiler bulunamamasını da açıklamaktadır.

Sıradan ihlaller boyutu ile cinsiyet arasında (erkek olmak) pozitif yönde anlamlı bir ilişki bulunmuştur. İlgili literatür incelendiğinde sürücülerin, trafik ortamındaki davranışları üzerinde yaş ve cinsiyetlerinin de etkili olduğu bilinmektedir (Newnam, Mamo ve Tulu, 2014; Soliman, Alhajyaseen, Alfar ve Alkaabi, 2018). Yapılan çalışmalara göre genç erkek sürücüler, genç kadın sürücülerden daha fazla sıradan ihlal sergilemektedir (Özkan ve Lajunen, 2005). Sıradan ihlaller ile akıllı telefon bağımlılı̆̆ı arasında pozitif yönde anlamlı bir ilişki bulunmuştur. İhlaller, sürücülerin seyir halindeyken kendilerinin ve diğer yol kullanıcılarının can ve mal bütünlüğünü tehdit eden davranışları niyetli olarak sergilemesi ve yol kurallarını göz ardı etmesi olarak tanımlanmaktadır (Reason ve ark., 1990; Lawton, Parker, Manstead ve Stradling, 1997). Sıradan ihlaller ise kişinin trafik kurallarına niyetli bir şekilde uymadığı ancak başka yol kullanıcısına bilinçli olarak zarar vermeyi amaçlamadığı davranışlardır (Warner, Özkan, Lajunen ve Tzamalouka, 2011). Sürüş esnasında, sürücülerin akıllı telefon kullanmaları dikkati dağınık bir şekilde araç kullanma tanımına girdiğinden ilgili trafik kurallarına aykırı bir davranış olup, diğer yol kullanıcılarını kasıtlı olarak incitmeyi hedefleyen bir davranış olmadığı için sıradan ihlal olarak değerlendirilmektedir. İlgili literatürde de dikkati dağınık şekilde araç kullanmak ile sıradan ihlaller arasında benzer şekilde pozitif yönde kuvvetli ilişkiler olduğu görülmektedir (Feng, Marulanda ve Dönmez, 2014). Bu yüzden, siradan ihlaller ile akıllı telefon bağımlılığı arasındaki pozitif yöndeki ilişki anlaşılır görülmektedir.

Agresif ihlaller boyutu ile akıllı telefon bağımlılı̆̆ı arasında yine pozitif yönde bir ilişki bulunmuştur. Agresif ihlaller, diğer yol kullanıcılarına yönelik kızgın davranmak düşmanlık

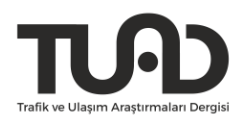


göstermek gibi saldırgan niyetler içeren sürücü davranışları şeklinde tanımlanmaktadır (Reason ve ark., 1990; Lawton ve ark., 1997). Yapılan literatür taramasında agresif ihlaller ve akıllı telefon bağımlılığı arasındaki ilişkiyi inceleyen bir çalışma bulunmamakla birlikte, kişilik özelliklerinin hem agresif ihlaller hem de bağımlılık ile ilişkili olduğu görülmüştür. Yapılan çalışmalar anksiyete, depresyon, olumsuz benlik gibi psikolojik belirtiler ve nevrotiklik ile internet bağımlılığı arasında anlamlı ilişkiler olduğunu göstermektedir (Batıgün ve Kılıç, 2011). Olumsuz kişilik özelliklerine sahip sürücülerin ise trafik ortamında da zarar verici ve saldırganca davranışlar sergilemeleri beklenebilmektedir (Constantinou, Panayiotou, Konstantinou, Loutsiou-Ladd ve Kapardis, 2011). Xu ve ark. (2018) tarafindan yapilan bir çalışmada nevrotik kişilik özelliği ile agresif ihlaller arasında anlamlı ilişkiler bulgulanması bu beklentiyi desteklemektedir. Tüm bu bilgiler doğrultusunda, akıllı telefon bağımlılığının ile agresif ihlaller ile arasındaki ilişki, internet bağımlılığı ve kişilik özellikleri temelinde düşünüldüğünde literatür ve beklentiler ile tutarlılık göstermektedir.

İhmaller boyutu ile akıllı telefon bağımlılı̆̆ı arasında yine pozitif yönde bir ilişki bulunmuştur. İhmal sürücülerin hız sınırı, trafik 1şıkları, takip mesafesi gibi yol kurallarını niyetli bir şekilde görmezden gelmesidir (Lawton ve ark.,1997). Literatürde ihmallerin yanlış kararlar ve dalgınlık gibi bilişsel süreçlerle ilişkili olduğu bulunmuştur (Sümer ve ark., 2002). Bu çalışmada ihmaller ile cinsiyet arasında herhangi bir ilişki bulunamamıştır. İlgili literatür incelendiğinde ihmaller ile cinsiyet ve yaş arasında anlamlı ilişkiler gösterdiği bulunmuştur. Sümer ve ark. (2002) tarafından yapılan bir çalışmaya göre kadın ve yaşlı sürücüler daha fazla ihmal davranışı gösterme eğilimindedir. Yapılan farklı çalışmalar da ihmallerin, sürücünün niyetli davranışlarından farklı olarak hafıza ve dikkat gibi bilişsel süreçlerde meydana gelen aksaklıklardan kaynaklanabileceğini belirtmektedir (Özer ve Öz, 2018). Trafik ortamında, dikkat dağınıklığının en güçlü yordayıcılarından birisinin, sürücünün sürüş esnasında akıllı telefon kullanımı olduğu bilinmektedir (Amerikan Ulusal Karayolu Trafik Güvenliği İdaresi [NHTSA], 2011). Sürücülerin, akan trafikte akıllı telefon kullanmaları hafiza ve dikkat gibi bilişsel süreçlerinde aksamalara sebep olmaktadır (Watson ve ark., 2016). Bu bilgiler bağlamında, sürüş esnasında akıllı telefon kullanımının ihmal gibi niyetsiz oluşan davranışlarla ilişkili olabileceği düşünülmektedir.

Çalışmanın örnekleminin cinsiyetler arasında sayı eşitliğinin sağlanamadığı nispeten az kişi ile yapılmış olması çalışmanın bir kısıtlılığı olarak gösterilebilir. Yapılacak sonraki çalışmalarda her iki cinsiyet grubundan da eşit sayıda ve daha fazla kişiye ulaşılması önerilebilir. Çalışmanın bulguları yorumlanırken göz önünde tutulması gereken bir diğer önemli nokta ise bulguların nedensellik sonucuna dayanmadığı, değişkenler arasındaki ilişkiselliği incelediğidir. Akıllı telefon bağımlılığının sürücü davranışları üzerinde bozucu bir etkisinin olup olmadı̆̆ının net olarak söylenebilmesi için ileride yapılacak çalışmalarda deneysel desenin kullanılmasının gerektiği söylenebilir.

\subsection{Sonuç ve Öneriler}

Bu çalışmada sürücü davranışları ile sürücülerin akıllı telefon bağımlılıkları arasındaki ilişkinin incelenmesi amaçlanmıştır. Bu çalışma Türkçe literatürde akıllı telefon bağımlılığı ve sürücü davranışları arasındaki ilişkiyi inceleyen ilk çalışma olma özelliğini taşımaktadır. Uluslararası literatüre bakıldığında ise konunun daha çok dikkati dağınık sürücülük kapsamında çalışıldığ 1 görülmektedir. Bu sebeple çalışmada elde edilen sonuçların ilgili literatüre önemli katkıları da olacağı düşünülmektedir.

Literatürde trafik ortamında akıllı telefon kullanımının, sürücülerin dikkatini dağıttığı ve kaza yapma riskini dört kat arttırdığı bilinmektedir (DSÖ, 2011). Akıllı telefon bağımlılığı ile sürücü davranışları arasındaki ilişki, akıllı telefon bağımlılığının sürücü davranışlarının tüm alt

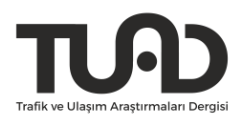


boyutları ile pozitif yönde güçlü ilişkiler içinde olduğunu göstermektedir. $\mathrm{Bu}$ bulgu, günümüzde oldukça artan akıllı telefon kullanımının trafikte yol açabileceği problemlere işaret ettiğinden dolayı oldukça önemlidir. Gelişen teknoloji akıllı cihazlar kişilerin günlük hayatlarında gittikçe artan bir yer kaplamaktadır. Bu sebeple bu teknolojilerin trafikte ilişkili olabileceği davranışların incelenmesi ayrı bir önem taşımaktadır. Özellikle, teknoloji kullanım yaşının düşmesi ve gençlerin gitgide daha fazla miktarda akıllı telefon kullanıyor olmaları zaten riskli bir sürücü grubu olan genç sürücüler için daha da fazla risk oluşturmaktadır. $\mathrm{Bu}$ bağlamda, kamu genelinde araç kullanırken telefon kullanmaya bağlı dikkat dağınıklığına yönelik çalışmalara ve özellikle okullarda gençlerin akıllı telefon bağımlılıklarına yönelik çalışmalara önem verilmelidir. Son olarak, çalışmada elde edilen bulguların kural koyucuların trafik kazaların büyük çoğunluğunun zeminini oluşturan sürücü davranışlarını düzenlemeye yönelik kanunlar ve sınırlamalar geliştirmesinde faydalı olabileceği düşünülmektedir.

\section{Yazar Notları:}

Yazarlar soyadı sırasına göre alfabetik olarak sıralanmıştır. 


\section{Kaynakça}

Aktaş, H. ve Yılmaz, N. (2017). Üniversite gençlerinin yalnızlık ve utangaçlık unsurları açısından akıllı telefon bağımlılı̆̆ı. International Journal of Social Sciences and Education Research, 3(1), 85-100. doi:10.24289/ijsser.283590

Amerikan Ulusal Karayolu Trafik Güvenliği İdaresi (2011). Driver electronic device use in 2010. https://crashstats.nhtsa.dot.gov/Api/Public/ViewPublication/811517 adresinden edinilmiştir.

Asbridge, M., Brubacher, J. R. ve Chan, H. (2012). Cell phone use and traffic crash risk: A culpability analysis. International Journal of Epidemiology, 42(1), 259-267. doi:10.1093/ije/dys 180

Bank of America (2015). Trends in Consumer Mobility Report. https://promo.bankofamerica.com/mobilityreport/assets/images/2015-Trends-inConsumer-Mobility-Report_FINAL.pdf adresinden edinilmiştir.

Batıgün A. D. ve Kılıç, N. (2011). İnternet bağımlılığı ile kişilik özellikleri, sosyal destek, psikolojik belirtiler ve bazı sosyo-demografik değişkenler arasındaki ilişkiler. Türk Psikoloji Dergisi, 26(67), 1-10.

Boyce, T. E. ve Geller, E. S. (2002). An instrumented vehicle assessment of problem behavior and driving style: Do younger males really take more risks? Accident Analysis and Prevention, 34(1), 51-64. doi:10.1016/S0001-4575(00)00102-0

Constantinou, E., Panayiotou, G., Konstantinou, N., Loutsiou-Ladd, A. ve Kapardis, A. (2011). Risky and aggressive driving in young adults: Personality matters. Accident Analysis and Prevention, 43(4), 1323-1331. doi:10.1016/j.aap.2011.02.002

Dahlen, E. R. ve White, R. P. (2006) The Big Five factors, sensation seeking and driving anger in the predictors of unsafe driving. Personality and Individual Differences, 41(5), 903915. doi:10.1016/j.paid.2006.03.016

Dragutinovic, N. ve Twisk, D. (2005). Use of mobile phones while driving effects on road safety. SWOV Institude for Road Safety Research.

Drews F. A. ve Strayer, D. L. (2008). Effects of distraction on driving performance. Driver distraction: Theory, effects and mitigation (1. baskı) içinde (s. 169-190). Boca Raton: CRC Press.

Dünya Sağlık Örgütü (2011). Mobile Phone Use: A Growing problem of driver distraction. https://www.who.int/violence_injury_prevention/publications/road_traffic/distracted_ driving_en.pdf adresinden edinilmiştir.

Eby, D. W. ve Vivoda, J. M. (2003). Driver hand-held mobile phone use and safety belt use. Accident Analysis and Prevention, 35(6), 893-895. doi:10.1016/S0001-4575(02)000969

Elander, J., West, R. ve French, D. (1993). Behavioral correlates of idividual differences in road-traffic crash risk: An examination of methods and findings. Psychological Bulletin, 113(2), 279-294. doi:10.1037/0033-2909.113.2.279

Engelberg, J. K., Hill, L. L., Rybar, J. ve Styer, T. (2015). Distracted driving behaviors related to cell phone use among middle-aged adults. Journal of Transport and Health, 2(3), 434-440. doi:10.1016/j.jth.2015.05.002

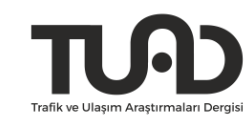


European Survey of Road Users Safety Attitudes (ESRA) (2016).

Feng, J., Marulanda, S. ve Donmez, B. (2014). Susceptibility to driver distraction questionnaire: development and relation to relevant self-reported measures. Transportation Research Record: Journal of the Transportation Research Board, 2434, 26-34.

Fındık, G., Lajunen, T. ve Özkan, T. (2018). Profesyonel sürücülerde mesleki stres ve sapkın sürücü davranışları ilişkisinde tükenmişlik seviyesinin aracı rolü. Trafik ve Ulaşım Araştırmaları Dergisi, 1(1), 1-13.

Fowler, J. ve Noyes, J. (2017, March). Are there health risks for teenagers using mobile phones? A study of phone use amongst 14-18 year olds. In Occupational Safety and Hygiene V: Selected papers from the International Symposium on Occupational Safety and Hygiene (SHO 2017), April 10-11, 2017, Guimarães, Portugal (s. 59). CRC Press.

Gershon, P., Zhu, C., Klauer, S. G., Dingus, T. ve Simons-Morton, B. (2017). Teens' distracted driving behavior: Prevalence and predictors. Journal of Safety Research, 63, 157-161. doi:10.1016/j.jsr.2017.10.002

Hassan, H. M. ve Abdel-Aty, M. A. (2013). Exploring the safe implications of young drivers' behaviour, attitudes and perceptions. Accident Analysis and Prevention, 50, 361-370. doi:10.1016/j.aap.2012.05.003

Lajunen, T. ve Özkan, T. (2004). Culture, safety culture, and traffic safety in Turkey and in Europe. The Turkish Driver Behaviour Questionnaire (T-DBQ): Validity and norms. Report no: SBB-3023. The Scientific and Technical Research Council of Turkey (TUBITAK), June 2004, Ankara, Turkey.

Lam, L. T. (2003). Factors associated with young drivers' car crash injury: Comparisons among learner, provisional and full licensees. Accident Analysis and Prevention, 35(6), 913920. doi:10.1016/S0001-4575(02)00099-4

Lepp, A., Li, J., Barkley, J. E. ve Salehi-Esfahani, S. (2015). Exploring the relationships between college students' cell phone use, personality and leisure. Computers in Human Behavior, 43, 210-219. doi:10.1016/j.chb.2014.11.006

Latwon, R., Parker, D., Manstead, A. S. R. ve Stradling, S. G. (1997). The role of affect in predicting social behaviours: The case of road traffic violations. Journal of Applied Social Psychology, 27(14), 1258-1276. doi:10.1111/j.1559-1816.1997.tb01805.x

Li, X., Yan, X. ve Wong, S. C. (2015). Effects of fog, driver experience and gender on driving behavior on S-curved road segments. Accident Analysis and Prevention, 77, 91-104. doi:10.1016/j.aap.2015.01.022

Newnam, S., Mamo, W.G. ve Tulu, G.S. (2014). Exploring differences in driving behaviour across age and years of education of taxi drivers in Addis Ababa, Ethiopia. Safety Science, 68, 1-5. doi:10.1016/j.ssci.2014.02.012

Noyan, C. O., Enez-Darçın, A., Nurmedov, S., Yılmaz, O. ve Dilbaz, N. (2015). Akıllı telefon bağımlılığı ölçeğinin kısa formunun üniversite öğrencilerinde Türkçe geçerlilik ve güvenirlik çalışması. Anadolu Psikiyatri Dergisi, 16(1), 73-81. doi:10.5455/apd.176101

Özer, Ö. ve Öz, B. (2018). Sürücü davranışlarının kişilerarası döngüsel model üzerindeki temsilleri. AYNA Klinik Psikoloji Dergisi, 5(1), 32-49. 
Özkan, T. ve Lajunen, T. (2005). Multidimensional traffic locus of control scale (T-LOC): factor structure and relationship to risky driving. Personality and Individual Differences, 38(3), 533-545. doi:10.1016/j.paid.2004.05.007

Öztürk, İ. (2017). Young driver behaviors in relations to the implicit and explicit driving skills. Psikoloji Anabilim Dalı, Orta Doğu Teknik Üniversitesi Sosyal Bilimler Enstitüsü. Yüksek Lisans Tezi. Ankara.

Parr, M. N., Ross, L. A., McManus, B., Bishop, H. J., Wittig, S. M. O. ve Stavrinos, D. (2016). Differential impact of personality traits on distracted driving behaviors in teens and older adults. Accident Analysis and Prevention, 92, 107-112. doi:10.1016/j.aap.2016.03.011

Poó, F. M. ve Ledesma, R. D. (2012). A Study on the relationship between personality and driving styles. Traffic Injury Prevention, 14(4), 346-352. doi:10.1080/15389588.2012.717729

Reason, J., Manstead, A., Stradling, S., Baxter, J. ve Campbell, K. (1990). Errors and violations on the roads. Ergonomics, 33(10-11), 1315-1332. doi:10.1080/00140139008925335

Regan M. (2007). Driver distraction: Reflections on the past, present and future. In: Faulks IJ et al, eds. Distracted driving. Sydney, Australasian College of Road Safety, 29-73.

Regan, M.A., Hallet, C. ve Gordon, C.P. (2011). Driver distraction and driver inattention: Definition, relationship and taxonomy. Accident Analysis and Prevention, 43(5), 17711781. doi:10.1016/j.aap.2011.04.008

Regan, M. A., Lee, J. D. ve Young, K. L. (2008). Driver Distraction. CRC Press.

Saiprasert, C., Supakwong, S., Sangjun, W. ve Thajchayapong, S. (2014). Effect of smartphone usage on driver safety level performance in urban road conditions. 11tn International Conference on Electrical Engineering/Electronics, Computer, Telecommunations and Information Technology (ETCI-CON). doi:10.1109/ECTICon.2014.6839778.

Soliman, A., Alhajyaseen, W., Alfar, R. ve Alkaabi, İ. (2018). Changes in driving behavior across age cohorts in an Arab culture: The case of state of Qatar. Procedia Computer Science, 130, 652-659. doi:10.1016/j.procs.2018.04.116

Sümer, N., Lajunen, T. ve Özkan, T. (2002). Sürücü davranışlarının kaza riskindeki rolu: İhlaller ve hatalar. (Sözlü sunum). Uluslararası Trafik ve Yol Güvenliği Kongresi, Ankara. $\quad$ http://www.trafik.gov.tr/SiteAssets/Yayinlar/Bildiriler/pdf/A4-4.pdf sitesinden edinilmiştir.

Şata, M., Çelik, İ., Ertürk, Z. ve Taş, U.E. (2016). Akıllı telefon bağımlılığı ölçeği’nin (ATBÖ) Türk lise öğrencileri için uyarlama çalışması. Eğitimde ve Psikolojide Ölçme ve Değerlendirme Dergisi, 7(1), 156-169. doi:10.21031/epod.95432

Thomée, S., Härenstam, A. ve Hagberg, M. (2011). Mobile phone use and stress, sleep disturbances, and symptoms of depression among young adults-a prospective cohort study. BMC Public Health, 11(1), 66. doi:10.1186/1471-2458-11-66

Türkiye İstatistik Kurumu (2018, Eylül). Haberleşme Verileri. 
Uzgören, E., Şengür, M. ve Yiğit, Ü. (2013). Üniversite öğrencilerinin cep telefonu talebinde israfa yönelik davranışların analizi. Dumlupınar Üniversitesi Öğrencilerine Yönelik Bir Uygulama. Süleyman Demirel Üniversitesi İktisadi ve İdari Bilimler Fakültesi Dergisi, 18(1), 29-44.

Yıldiz, A. ve Selek, H. S. (2018). Danger risks from mobile phones and base stations and occupational health and safety analysis. Journal of Current Researches on Social Sciences, 8(4), 547-566.

Young, K. L., Salmon, P. M. ve Cornelissen, M. (2013). Distraction-induced driving error: An on-road examination of the errors made by distracted and undistracted drivers. Accident Analysis and Prevention, 58, 218-225. doi:10.1016/j.aap.2012.06.001

Zhang, L., Xing, H., Qian, J., Jia, N. ve Liu, Y. (2018). How risk perception affect driving behaviors in disasters. The 4th ACM AIGSPATIAL International Workshop on Safety and Resilience - Safety and Resilience'18, Seattle: USA, doi:10.1145/3284103.3284126.

Warner, H. W., Özkan, T., Lajunen, T. ve Tzamalouka, G. (2011). Cross-cultural comparison of drivers' tendency to commit different aberrant driving behaviours. Transportation Research Part F: Traffic Psychology and Behaviour, 14(5), 390-399.

Wang, Z., Zheng, Z. ve Fleiter, J. J. (2016). Does family background impact driving attitudes and risky behaviours? An investigation on Chinese young drivers. Accident Analysis and Prevention, 95, 67-77. doi:10.1016/j.aap.2016.06.025

Watson, J. M., Memmott, M. G., Moffitt, C. C., Coleman, J., Turrill, J., Fernández, A. ve Strayer, D. L. (2016). On working memory and a productivity illusion in distracted driving. Journal of Applied Research in Memory and Cognition, 5(4), 445-453. doi:10.1016/j.jarmac.2016.06.008

Weller, J. A. Shackleford, C. Dieckmann, N. ve Slovic, P. (2013). Possession Attachment Predicts Cell Phone Use While Driving. Health Psychology, 32(4), 379-387. doi:10.1037/a0029265

Xu, J., Liu, J., Sun, X., Zhang, K., Qu, W. ve Ge, Y. (2018). The relationship between driving skill and driving behaviour: Psychometric adaption of the Driver Skill Inventory in China. Accident Analysis and Prevention, 120, 92-100. doi:10.1016/j.aap.2018.07.032 